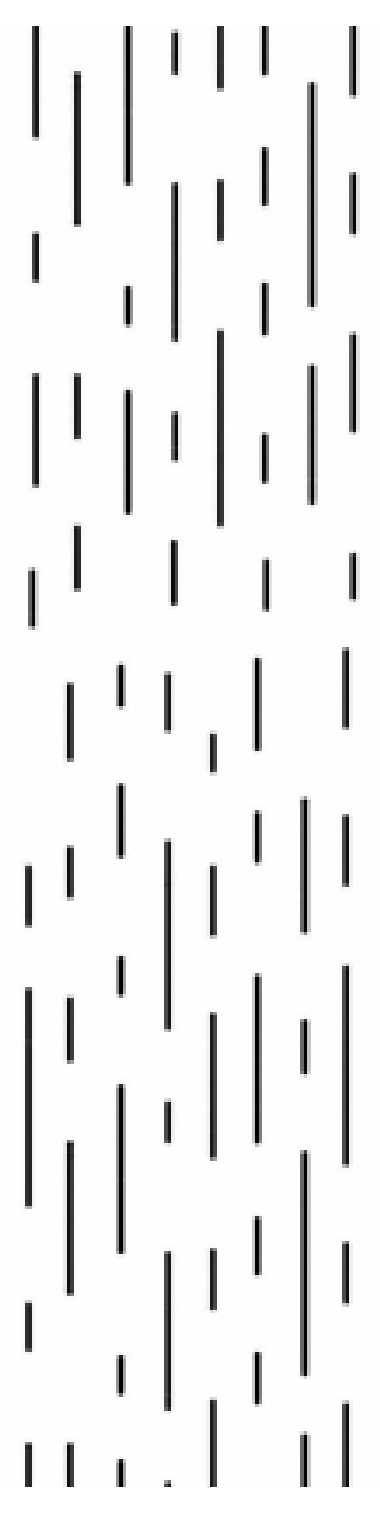

\title{
Inovação na Educação Superior
}

Marcos Masetto

\section{Organizando idéias}

O inter esse pela temática da Inovação na Educação Superior foi despertado pelo contato recente com palestras, artigos, livros e projetos sobre o assunto, com diferentes conotações, a saber: utilizar Novas Tecnologias de Informação e Comunicação na prática docente; prover os alunos de computadores para suas anotações e trabalhos escolares; dispor de laboratórios de informática; substituir aulas expositivas por trabalhos em grupo; trabalhar com ensino a distância.

Considerando minha experiência de quarenta anos de docência e pesquisa sobre ensino na universidade, levanto algumas reflexões visando contribuir para o debate atual sobre o tema, a partir do conceito de inovação na educação superior, entendida como o conjunto de alterações que afetam pontos-chave e eixos constitutivos da organização do ensino universitário provocadas por mudanças na sociedade ou por reflexões sobre concepções intrínsecas à missão da Educação Superior.

1 Examinando o primeiro elemento constitutivo do conceito, entre as alterações que afetam pontos-chave e eixos constitutivos da organização do ensino universitário, pode-se considerar:

- o projeto pedagógico de um curso ou de uma Instituição, desde sua criação (pela inexistência dele) até alterações no projeto existente, por força de novas exigências da sociedade ou de novas políticas governamentais;

- a explicitação de objetivos educacionais mais amplos incluindo, além dos aspectos cognoscitivos, habilidades e competências humanas e profissionais e atitudes e comportamentos exigidos pela sociedade atual, como ética, política, profissionalismo;

- a re-organização e flexibilização curricular para atender às novas exigências do projeto pedagógico ou de novas metas educacionais;

\footnotetext{
1 Professor do Departamento de Fundamentos da Educação e do Programa de Pós-Graduação em Educação e Currículo da Pontifícia Universidade Católica (PUC-SP); professor do Programa de Pós-Graduação em Educação, Arte e História da Cultura da Universidade Presbiteriana Mackenzie. <mmasetto@ajato.com.br>
} 
- a reconceptualização do papel das disciplinas como componentes curriculares, selecionadas em função dos objetivos formativos pretendidos e como fonte de informações necessárias para o profissional que se pretende formar;

- a integração das disciplinas e atividades curriculares em função dos objetivos educacionais, superando o isolamento e a fragmentação do conhecimento;

- a substituição da metodologia tradicional, baseada apenas em aulas expositivas, por metodologias que favoreçam o alcance dos vários objetivos educacionais, estimulem o aluno para aprender e possibilitem sua participação no processo de aprendizagem;

- a exploração das novas tecnologias, baseadas na informática, telemática, internet, propiciando atividades a distância, fora do espaço sala de aula, ao mesmo tempo estimulando o aluno para o encontro com o professor e os colegas;

- a revisão do conceito de avaliação, entendendo-a como avaliação formativa, instrumento de feedback (retro-informação) que motive o aluno para aprender, colabore para o seu desenvolvimento integral, o acompanhe em seu processo de aprendizagem de forma contínua, e que, com a colaboração de colegas, professor e do próprio aluno (auto- avaliação), consiga ampliar e aprofundar sua aprendizagem;

- a substituição do papel do professor de ministrador de aulas e transmissor de informações para o papel de mediador pedagógico, desenvolvendo relação de parceria e co-responsabilidade com seus alunos, trabalhando em equipe;

- a preparação dos professores para se comprometerem com a inovação e assumirem projetos inovadores, mediante um trabalho de formação docente contínua e em serviço que possibilite a reflexão sobre suas atividades docentes, o intercâmbio de experiências com colegas e o diálogo entre as áreas;

- a revisão de infraestrutura de apoio para projetos inovadores, incluindo biblioteca atualizada e informatizada, laboratórios adequados, preparação dos novos ambientes de aprendizagem.

2 Considerando o segundo elemento constitutivo de conceito de inovação apresentado - alterações provocadas por mudanças na sociedade sabe-se que por muito tempo o sistema universitário brasileiro vem se organizando conforme o modelo francês-napoleônico, voltado principalmente para a formação de profissionais, a partir de currículos inicialmente transpostos de universidades européias, com alter ações posteriores que não afetaram significativamente o modelo original.

Nas últimas três décadas, a sociedade brasileira vem sofrendo profundas alterações, provocadas principalmente pela nova revolução tecnológica da informática e da telemática que, além de afetar a vida cotidiana das pessoas, atinge o setores fundamentais da vida universitária.

Na chamada "Sociedade do Conhecimento" somos bombardeados com informações procedentes das mais longínquas regiões do globo, disseminadas rapidamente através da Internet, de sites especializados, da

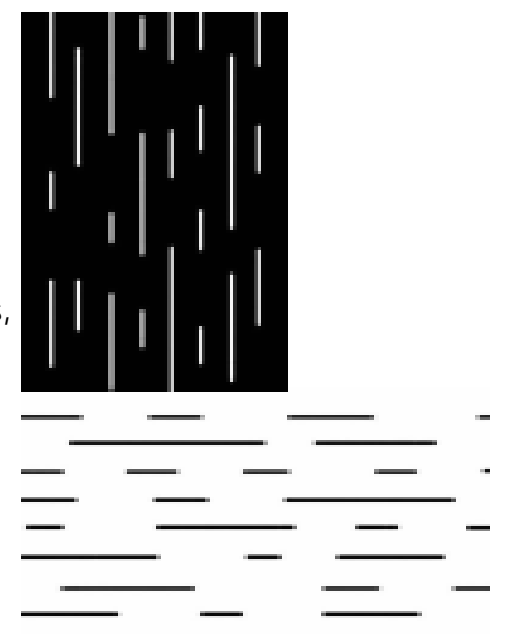


mídia, das revistas de grande circulação, que abordam assuntos outrora só encontrados em periódicos científicos. Tais informações, ao mesmo tempo em que nos atualizam, deixam uma sensação de impotência em relação a acompanharmos tudo o que acontece, mesmo que fiquemos restritos a nossa área de especialização.

Mas sendo o conhecimento a matéria prima de trabalho da escola, em particular da educação superior, é preciso avançar na reflexão sobre as conseqüências das alterações na sociedade, trazidas pela tecnologia, para o trabalho acadêmico na universidade, a exigir mudanças profundas na cultura organizacional da instituição. Para que essas mudanças aconteçam, sabe-se que é preciso, no mínimo: abertura, diálogo, intercomunicação e parceria com as mais diversas fontes de produção de conhecimento; revisão e reformulação de bancos de dados e informações; implantação de novos processos informativos e de comunicação.

Por outro lado, as atuais demandas da "Sociedade do Conhecimento" levam a uma crise das próprias carreiras profissionais, pela exigência de novas habilidades e competências, sem desconsiderar a competência técnica: trabalho em equipe, adaptação a situações novas, aplicação de conhecimento e aprendizagens, atualização contínua pela pesquisa, abertura à crítica, busca de soluções criativas, inovadoras, fluência em vários idiomas, domínio do computador e de processos de informática, gestão de equipe, diálogo entre pares. Tais exigências afetam diretamente a universidade em seu papel de formação do profissional exigido pela sociedade atual. O que necessariamente leva a se pensar em inovação na educação superior.

Além disto, as atuais políticas governamentais para a Educação Superior, independentemente dos princípios que as provocaram, têm dado espaço para propostas de inovação no ensino de graduação e na pesquisa em diferentes áreas do conhecimento, envolvendo parcerias entre organizações da mesma área, com objetivos comuns, ou entre organizações de áreas diferentes com objetivos afins. A educação superior e a pesquisa na universidade estão exigindo cada vez mais o conhecimento interdisciplinar, cooperativo, integrado.

3 Finalmente, uma breve reflexão sobre o último componente constitutivo do conceito de inovação apresentado - alterações que traduzem na vida das instituições as reflexões atuais sobre concepções intrínsecas à missão da Educação Superior.

Revendo a Declaração Mundial sobre Educação Superior no Século XXI: Visão e Ação da UNESCO, esta defende a missão do Ensino Superior voltada para a formação de pessoas altamente qualificadas e cidadãos responsáveis, aprendizagem permanente, promoção, geração e difusão da pesquisa e proteção e consolidação de valores atuais. Destaca a função ética da universidade, a necessidade de refor çar a cooperação da Academia com o mundo do trabalho, analisando e prevenindo as necessidades da sociedade. $O$ documento da UNESCO explicita, ainda, alguns aspectos a exigir mudanças essenciais, inovadoras, na educação superior: nos currículos, métodos pedagógicos, na formação contínua de professores, incluindo a formação pedagógica; além da incorporação crítica da tecnologia, da educação a

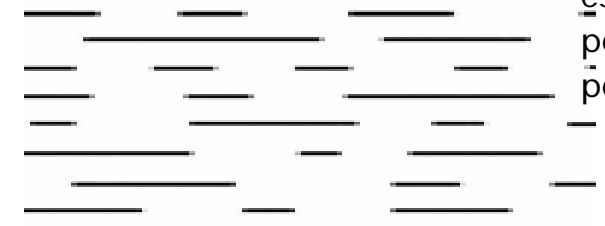


distância e da compreensão e exploração dos ambientes virtuais. Tais pontos poderão provocar inovações significativas e relevantes na Educação Superior.

Além destes, outros indicadores da inovação estão na pauta atual das discussões acadêmicas. $O$ ensino com pesquisa na graduação e o uso de novas tecnologias na sala de aula, são defendidos como propostas de tornar o estudante universitário sujeito do processo de aprendizagem, alterando radicalmente a disposição anterior de se entregar todas as informações já prontas e sistematizadas pelo professor para memorização e reprodução. A valorização da parceria e co-participação entre professores e alunos e entre os próprios alunos na dinamização do processo de aprendizagem e de comunicação se justificam pela necessidade de gerar novas formas de trabalho pedagógico e aproveitamento das atividades escolares. Defende-se, por fim, o papel do professor como educador responsável pela mediação pedagógica, que estimule a aprendizagem do aluno como processo pessoal e grupal, oriente seus trabalhos, discuta com ele suas dúvidas, seus problemas, incentivando a avançar no processo do conhecimento.

\section{Buscando interlocutores}

Autores da área da Administração (Drucher, 2000; Senge, 1996; Kanter, 1996) têm colocado a questão da inovação na pauta de debate atual sobre a crise das organizações sociais.

Drucker (2000) afirma que nos próximos cinqüenta anos as escolas e universidades sofrerão mudanças e inovações mais drásticas que nos seus últimos trezentos anos quando se organizaram em torno da mídia impressa. As novas tecnologias de informação e comunicação, a informática e a telemática, a perspectiva da aprendizagem contínua, ou seja, da "life long learning", têm criado novas demandas sociais, exigindo das organizações respostas inovadoras, uma vez que as soluções antigas já não se mostram suficientes e adequadas.

A organização para a mudança,

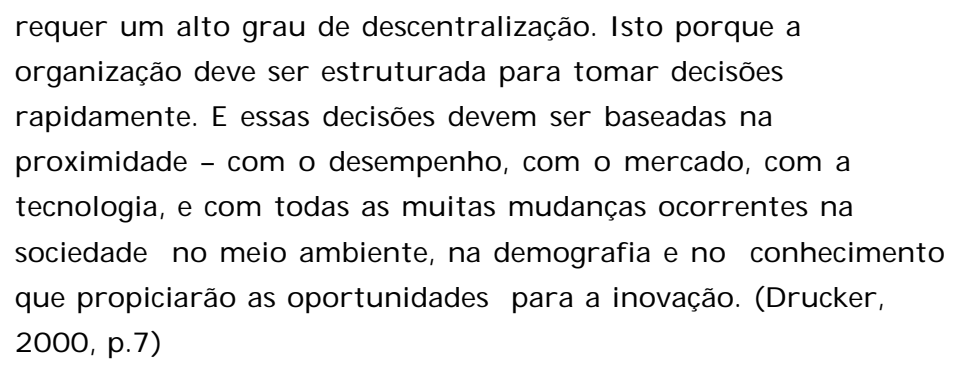

Senge (1996) chama atenção para uma atitude fundamental em qualquer inovação: o compromisso entre os que estão envolvidos no projeto de mudança, pois inovação e mudança andam juntas, mas só acontecem de fato quando as pessoas nelas envolvidas se abrem para aprender, para mudar, para adquirir novos conhecimentos, para alterar conceitos e idéias trabalhadas, às vezes, durante muitos anos, para assumir novos comportamentos e atitudes não comuns até aquele momento, para 
repensar a cultura pessoal e organizacional vivida até aquele momento, para mudar suas próprias crenças e aderir a novas e fundamentais maneiras de pensar e de agir.

Kanter (1996) focaliza outra grande característica da inovação: a parceria ou a capacidade de desenvolver fortes vínculos entre as organizações, defendendo que "cultura da empresa deva ser aberta em duas direções: ao cliente, cuja voz e visão são o melhor guia para o desenvolvimento dos produtos e a todo pessoal da empresa, cujas idéias devem ser ouvidas" (p.110). O desenvolvimento da organização passa pela linha da cooperação e da parceria, não mais pelo individualismo e fechamento de cada um em seu negócio.

Na área da educação, Imbernón (2000) desenvolve reflexões interessantes sobre os desafios do futuro imediato para a educação, muito próximas das idéias sobre inovação na educação superior trazidas na primeira parte deste trabalho, e destaca quatro idéias-força na base da mudança que deve impulsionar o futuro imediato da educação:

a recuperação por parte dos professores e demais agentes educativos do controle sobre seu processo de trabalho; a valorização do conhecimento, tanto daquele já adquirido e desenvolvido pelas gerações e culturas anteriores, que tem seu valor e importância mesmo nos dias de hoje, mas que se apresenta como insuficiente para os próximos tempos, quanto dos novos conhecimentos que são investigados e produzidos atualmente em novas condições de número de informações, de velocidade de comunicação e de proliferação de fontes de conhecimento; a valorização da comunidade como verdadeira integrante do processo educativo, da comunidade de aprendizagem, co-responsável pelo projeto pedagógico da instituição; a diversidade como projeto cultural e educativo. (Imbernón, 2000, p.80)

Procurando resumir seu pensamento sobre mudanças em educação, Imbernón (2000, p.85) identifica alguns imperativos:
um meio social baseado na informação e nas comunicações; a tendência a que tudo seja planejado; uma situação de crise em relação ao que se deve aprender e/ou ensinar em um mundo onde imperam a incerteza e a mudança vertiginosa; o novo papel do educador como gestor e mediador de aprendizagem.

Tais imperativos comportam novas exigências e demandas à instituição escolar e aos professores, em termos de uma nova concepção de trabalho educativo:

análise da obsolescência dos processos, dos materiais e das ferramentas de aprendizagem existentes; diagnóstico das novas necessidades dos alunos; busca de novas motivações dos alunos

Inteface- Comunic., Saúde, Educ., v.8, n.14, p.197-202, set.2003-fev.2004 
para a aprendizagem; grande influência do meio social na aprendizagem; busca de novos métodos; gestão coletiva da aprendizagem; utilização dos meios tecnológicos; formação permanente como parte intrínseca da profissão de educar e como compromisso na aprendizagem durante toda a vida. (Imbernón, 2000, p.89-90)

Neste espaço aberto a outras idéias que contribuam para o desenvolvimento de projetos inovadores para a educação superior, buscou-se sublinhar alguns aspectos essenciais do processo de mudança educativa, a refletir-se na formação de profissionais críticos e competentes, exigidos pela sociedade atual.

\section{Referências}

DRUCKER, P. A nova sociedade das organizações. In: HOWARD, R. (Org.) Aprendizado organizacional. Rio de Janeiro: Campus, 2000. p.1-7.

IMBERNÓN, F. (Org.) A educação no século XXI. Porto Alegre: ARTMED, 2000.

KANTER, R. M. Líderes da classe mundial: o poder da parceria. In: HESSELBEIN, F. ; GOLDSMITH, M.; BECKHARD, R. (Orgs.) O líder do futuro. São Paulo: Futura, 1996. p.100-5.

SENGE, P. Conduzindo organizações voltadas para o aprendizado: o destemido, o poderoso e o invisível. In: HESSELBEIN, F.; GOLDSMITH, M.; BECKHARD, R. (Orgs.) O líder do futuro. São Paulo: Futura, 1996. p.121-5.

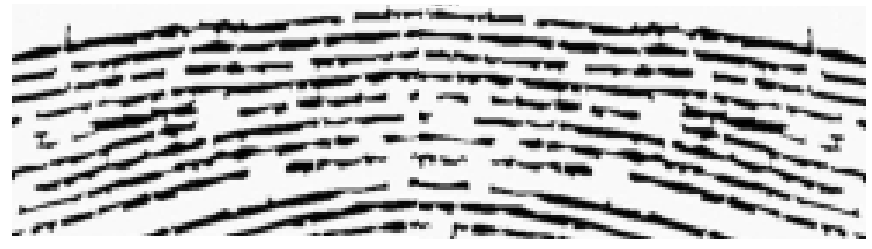

MASETTO, M. Innovation in higher education, Interface - Comunic., Saúde, Educ., v.8, n.14, p. , set.2003-fev.2004.

This paper discusses the concept of "Innovation" that is frequently found to mean changes in higher education. It explores features of the innovation process such as commitment, partnership and decentralization.

KEY WORDS: Organizational innovation; social change; higher education.

Este artigo discute o conceito de "inovação" freqüentemente encontrado referindo-se a mudanças na Educação Superior, explorando algumas características de um processo de inovação: compromisso, parceria, descentralização.

PALAVRAS-CHAVE: Inovação organizacional; mudança social; educação superior.

Este artículo discute el concepto de "innovación" que frecuentemente encontramos refiriéndose a alteraciones en la Enseñanza Superior. Presenta ideas que exploran algunas características de un proceso de innovación como por ejemplo, el compromiso, la asociación y el proceso de descentralización.

PALABRAS CLAVE: Innovación organizacional; cambio social; enseñanza superior. 